\section{Microrna Associated With Generation, Development, and Maintenance of Atrial Fibrillation}

\section{Fei Peng ${ }^{1}$, Hui Gong ${ }^{1 *}$, Lubna Nadeem ${ }^{2 *}$, Lingyun Zhang ${ }^{3}$ and Guoxiong $\mathrm{Xu}^{3 *}$}

${ }^{1}$ Division of Cardiology, Department of Internal Medicine, Jinshan Hospital, Fudan University, Shanghai 201508, China

${ }^{2}$ Lunenfeld Tanenbaum Research Institute, Mount Sinai Hospital, Toronto, Ontario M5T 3H7, Canada

${ }^{3}$ Center Laboratory, Jinshan Hospital, Fudan University, Shanghai 201508, China

\section{Abstract}

MicroRNAs (miRNAs) are a class of small non-coding RNAs, playing important roles in the regulation of the cardiovascular function. MiRNAs are associated with the generation, development, and maintenance of atrial fibrillation through the regulation of the gene expression on targets of ion channels, transporters, calcium binding proteins, extracellular matrix proteins, and other factors. Understanding the relationship between miRNAs and atrial fibrillation is critical to identifying the diagnostic markers, prognosis and therapeutic targets.

Keywords: MicroRNA; Atrial fibrillation; Gene regulation; Electrical remodeling; Structural remodeling
\end{abstract}

\section{Abbreviations}

AF: Atrial Fibrillation

Ang II: Angiotensin II

APD: Action Potential Duration

${ }^{*}$ Corresponding authors: Guoxiong Xu, Center Laboratory, Jinshan Hospital Fudan University, 1508 Longhang Road, Shanghai 201508, P.R. China, Tel: +86-21-34189990; Fax: +86-21-57039502; Email: guoxiong.xu@fudan.edu.cn

Lubna Nadeem, Lunenfeld Tanenbaum Research Institute, Mount Sinai Hospital, 600 University Avenue Toronto, Ontario M5T 3H7, Canada, Tel: +1-416-8900073; Email: nadeem@lunenfeld.ca

Hui Gong, Division of Cardiology, Department of Internal Medicine, Jinshan Hospital, Fudan University, 1508 Longhang Road, Shanghai 201508, P.R. China Tel: +86-13918566212; Fax: +86-21-67226910; Email: liyuanhn@aliyun.com

Citation: Peng F, Gong H, Nadeem L, Zhang L, Xu G (2014) Microrna Associated With Generation, Development, and Maintenance of Atrial Fibrillation. J Cardiol Stud Res 1: 003.

Received: June 10, 2014; Accepted: August 19, 2014; Published: September 02, 2014

Copyright: (c) 2014 Peng F, et al. This is an open-access article distributed under the terms of the Creative Commons Attribution License, which permits unrestricted use, distribution, and reproduction in any medium, provided the original author and source are credited.
AT1-R: Angiotensin II Type 1 Receptor

CACNA1C: Calcium Channel Voltage-Dependent L Type Alpha 1C Subunit

CACNB1: Calcium Channel Voltage-Dependent Beta 1 Subunit CaMKII: Calcium/Calmodulin-Dependent Protein Kinase II

COL1A1: Collagen Type I Alpha 1

COL3A1: Collagen Type III Alpha 1

CTGF: Connective Tissue Growth Factor

DGCR8: DiGeorge Syndrome Critical Region 8

ERK1/2: Extracellular Signal-Regulated Kinase1/2

ECM: Extracellular Matrix

ERP: Effective Refractory Period

GJA1: Gap Junction Alpha 1 Protein

$\mathrm{I}_{\mathrm{Ca}}{ }^{2+}$ : Intracellular Calcium Current

IK1: Inward Rectifier Potassium Current

KCNJ2: Inwardly-Rectifying Channel, Subfamily J, Member 2

KCNN3: Potassium intermediate/small conductance calcium-activated channel subfamily $\mathrm{N}$ member 3

LOX: Lysyl Oxidase

MAPK: Mitogen-Activated Protein Kinase

miR or miRNA: MicroRNA

mRNA: Messenger RNA

NF- $\kappa$ B: Nuclear Factor- $\kappa B$

PDCD4: Programmed Cell Death 4

PP2A: Protein Phosphatase

PTEN: Phosphatase and Tensin Homology

RAAS: Renin-Angiotensin-Aldosterone System

Rac1: Ras-Related C3 Botulinum Toxin Substrate 1

RISC: miRNA-Induced Silencing Complex

RNA: Ribonucleic Acid

RNase: Ribonuclease

RyR2: Ryanodine Receptor Type 2

SK3: Small-Conductance Calcium-Activated Potassium Channel 3

Spry1: Sprouty Homolog 1

TGF- $\beta$ : Transforming growth factor- $\beta$

TGF- $\beta$ RII: TGF- $\beta$ Receptor Type II

THRAP1: Thyroid Hormone-Associated Protein 1

UTR: Untranslated Region

\section{Introduction}

Atrial fibrillation (AF) is the most common sustained arrhythmia which affects quality of life drastically [1]. The incidence of $\mathrm{AF}$ is $16.8 \%$ and $7.6 \%$ in men and women, respectively [2]. AF can cause and exacerbate heart failure. Also it is a significant risk factor for ischemic stroke $[3,4]$ and therefore a major cause of cardiovascular morbidity and mortality [5]. Although a copious body of both basic and clinical research exists on AF, not all of the specific pathophysiological mechanisms of the generation, development and maintenance of AF are fully understood. Evidence shows that multiple factors are involved in the generation and development of AF. These factors include oxidative stress, systemic inflammation, autonomic imbalance, endocrine disorders, early electrical remodeling, such as shortened atrial effective refractory period (ERP) and action potential duration (APD) [6], and late mechanical remodeling, such as cardiac hypertrophy and myocardial fibrosis [7]. Recently a few studies have unveiled that miRNAs expression and/or deregulation can influence the generation, development and maintenance of AF. This review 
focuses on the current understanding about the role and function of miRNAs in AF.

\section{Biogenesis and Function of miRNAs}

MiRNAs are highly conserved, non-coding endogenous and single-stranded RNAs, which bind to the 3'-untranslated regions (UTRs) of target mRNAs to regulate the expression of target genes [8]. MiRNA-mediated post transcriptional gene regulation involves the degradation of the target mRNA or the suppression of its translation depending upon the sequence complementarity between the miRNA seed-sequence and the 3'-UTR of the target mRNA. Partial binding between seed sequence and target mRNA results in the repression of translation, whereas extensive pairing complementarity leads to the degradation of target mRNA [9-11].

The multiple-to-multiple relationship between miRNAs and their targets is recognised [12]. In such relationships one miRNA can target several genes and similarly several miRNAs or a miRNA cluster can target one single gene. Generally, the biological processes of miRNA biogenesis include four steps. First, generation/transcription of primary transcript called primary-miRNA (pri-miRNA) is mediated by RNA Polymerase II in the nucleus [9], which is then polyadenylated and capped by 7-methylguanosine [13]. Second, the pri-miRNA is cleaved by Drosha, a ribonuclease (RNase) III enzyme, with its co-activator partner, DGCR8 (DiGeorge Syndrome Critical Region 8, a microprocessor complex unit) to form precursor miRNA (pre-miRNA) [14,15]. The third step involves the cytosol export of pre-miRNA by the protein Exportin 5/Ran-GTP complex [16] and further cleavage into a mature miRNA by Dicer, another RNase III enzyme [14]. In the fourth and the last step, the double-stranded mature miRNA is dissociated and incorporated into the miRNA-induced silencing complex (RISC) which then targets complementary mRNAs [15,17] (Figure 1). Typically, miRNA expression is time and tissue type-specific [18].

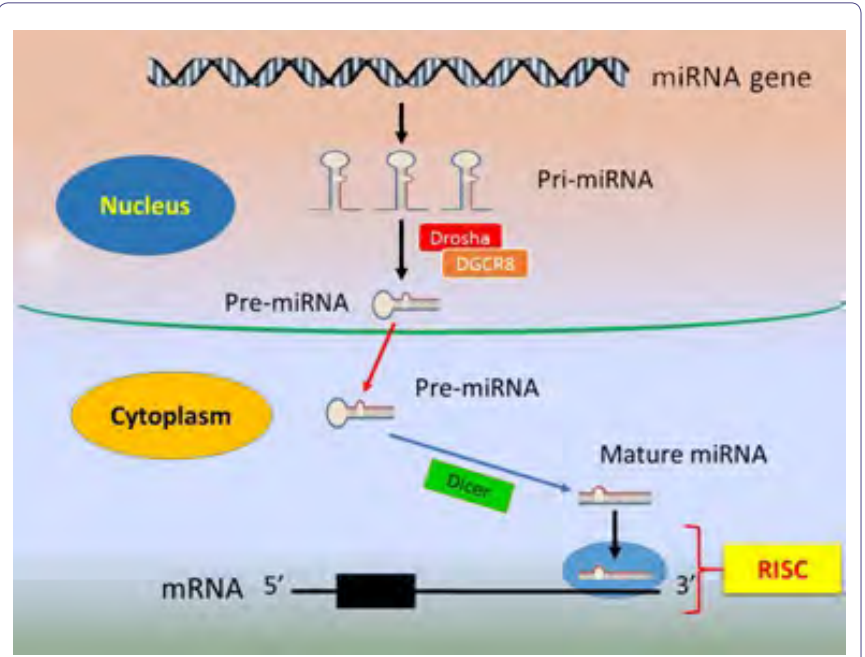

Figure 1: Biogenesis and function of miRNA.

The nucleus primary-miRNAs (pri-miRNA) are transcribed from long miRNA genes mediated by RNA polymerase II and cleaved by the ribonuclease III (RNase III) endonuclease Drosha with its partner DGCR8 to turn into precursor-miRNAs (pre-miRNA), which then move from the nucleus to the cytoplasm where the cytoplasmic enzyme Dicer further cleaves the pre-miRNA into double-stranded mature miRNA. The mature miRNAs are incorporated into the
RNA-induced silencing complex (RISC). A mature miRNA binds to its target mRNA at 3'-UTR, leading to mRNA degradation or transcriptional repression.

MiRNAs are associated with many physiological processes: embryonic development, cell proliferation, differentiation, apoptosis, autophagy, and tissue or organ formation and remodeling. Especially in the heart, miRNAs play a vital role in angiogenesis, fibrosis, myocardial cells regeneration, and cardiac remodeling and therefore considered to be strong potential tools for the diagnosis and treatment of heart related diseases [9,19-21]. MiRNAs can affect cardiomyocyte excitability and conductivity by the regulation of ion channels permeability, transporters and associated regulatory proteins which can lead to different forms of arrhythmias [22]. The expression of miRNA spectrum in atrial tissue is significantly different in mitral stenosis patients with AF compared with healthy subjects [23]. AF alters the miRNA expression profiles of the left atria of mitral stenosis patients [24], suggesting that miRNA may be involved in the generation and development of AF. In fact, AF is a complex pathology, involving both primary electrical and structure factors. Different miRNA families are associated with different aspects of AF (Table1).

\section{Role of miRNAs in the Generation and Regulation of $\mathrm{AF}$}

The mechanisms of AF are complex, but recent studies have shown that miRNAs contribute to the generation and regulation of $\mathrm{AF}$ in several ways (Figure 2). For example, miRNAs can induce cardiac immune/inflammatory response [38,39] and affect ion channels as well as structural and electrical remodeling including intracellular calcium overload [40]. These, in turn, can result in shortening of the action potential ERP and APD, which is conducive to the formation of reentry [4].

Two mechanisms generate and develop atrial fibrillation by making substrate more prone to reentry. MiR-1, miR-26, miR-328 and miR-499 regulate atrial electrical remodeling through the modulation of ion channel $\left(\mathrm{I}_{\mathrm{K} 1}, \mathrm{Ica}^{2+}\right)$ activity and expression. MiR-19, miR-21, miR-29, miR-30, miR-133, miR-155, miR-208 and miR-590 result in the increase of collagen secretion and extracellular matrix deposition which leads to atrial structural remolding. $I_{K 1}$, inward rectifier potassium current. $\mathrm{Ica}^{2+}$, intracellular calcium current.

\section{miR-29: Role in cardiac immune response}

MiR-29 has a crucial role in the generation and development of AF. The down-regulation of miR-29 can induce the fibrosis of the liver [41] and lung [42] and can also cause aneurysms [43]. The risk of AF prevalence is increased by $30 \%$ with celiac disease [44]. Overall, inflammation and chronic inflammatory diseases, such as psoriasis, also increase the risk of AF [45]. Therefore, AF is partially moderated by the humoral and systemic inflammatory response induced by local fibrosis. The miR-29 family (miR-29a, miR-29b and miR-29c) is expressed in T and B cells, dendritic cells and thymic epithelial cells, which play a regulatory role in the adaptive immune pathway [46]. Multiple biopsy specimens in left atria with AF have shown lymphocytic myocarditis in $66 \%$ of patients and noninflammatory localized cardiomyopathy in $17 \%$ of patients [47]. In the canine model of AF, miR-29b was found to target collagen-1 A1 (COL1A1), collagen-3A1 (COL3A1) and fibrilin [30], which are the prime markers of tissue remodeling. Moreover, the serum level of miR-29b is reduced in patients with AF by $54 \%$, strongly implicating 
Citation: Peng F, Gong H, Nadeem L, Zhang L, Xu G (2014) Microrna Associated With Generation, Development, and Maintenance of Atrial Fibrillation. J Cardiol Stud Res 1: 003 .

- Page 3 of 6 •

\begin{tabular}{|c|c|c|c|c|}
\hline miRNA & Target & Function & Possible role in AF & Reference \\
\hline miR-1 & KCNJ2 GJA1 RyR2 & Abnormal $\mathrm{Ca}^{2+}$ handling & Atrial electrical remodeling & [25] \\
\hline $\operatorname{miR}-19$ & CTGF & Extracellular matrix, myocardial fibrosis & Atrial structural remodeling & [26] \\
\hline miR-21 & $\begin{array}{l}\text { PDCD4 } \\
\text { PTEN }\end{array}$ & MMP-2 expression increase, extracellular matrix, myocardial fibrosis & Atrial structural remodeling & {$[27,28]$} \\
\hline $\operatorname{miR}-26$ & $\mathrm{KCNJ} 2$ & Ik1 increase & Atrial electrical remodeling & [29] \\
\hline $\operatorname{miR}-29$ & COL1A1 COL3A1 & Collagen secretion, inflammation & Atrial structural remodeling & [30] \\
\hline miR-30 & Ang II & Myocardial hypertrophy & Atrial structural remodeling & [31] \\
\hline miR-133 & ERK1/2 TGF- $\beta 1$ TGF- $\beta$ RII & Myoblast proliferation, myogenesis & Atrial structural remodeling & {$[32,33]$} \\
\hline miR-155 & AT1-R & Endothelial dysfunction, vascular remodeling, inflammation & Atrial structural remodeling & [34] \\
\hline miR-208 & THRAP1 myostatin & Myocardial hypertrophy & Atrial structural remodeling & [35] \\
\hline $\operatorname{miR}-328$ & CACNA1C CACNB1 & $\mathrm{Ica}^{2+}$ reduction & Atrial electrical remodeling & [36] \\
\hline $\operatorname{miR}-499$ & KCNN3 & Abnormal $\mathrm{Ca}^{2+}$ handling & Atrial electrical remodeling & [37] \\
\hline miR-590 & TGF- $\beta 1$ TGF- $\beta R \|$ & Collagen content increase & Atrial structural remodeling & [33] \\
\hline
\end{tabular}

Table 1: Different miRNAs with potential roles in atrial fibrillation.

Atrial fibrillation $(\mathrm{AF})$ is characterized by atrial electrical remodeling and structural remodeling.

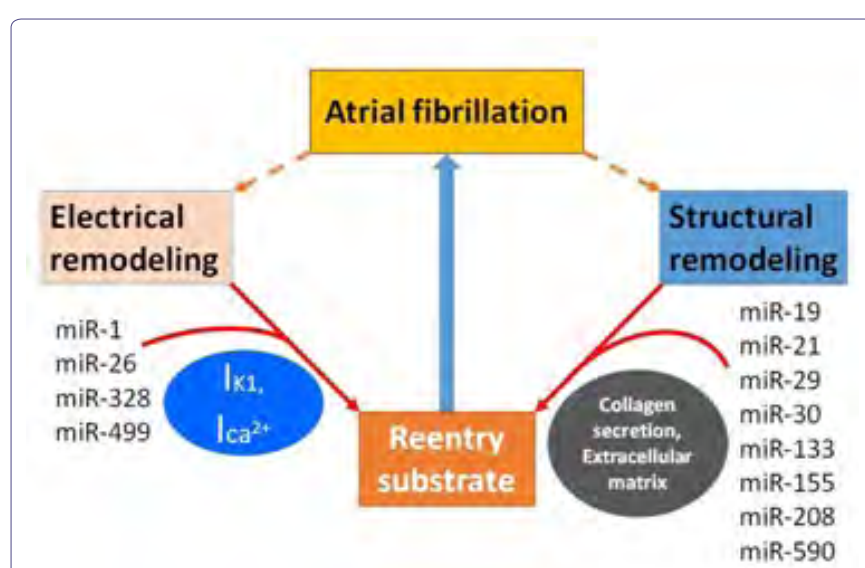

Figure 2: MiRNAs associated with atrial fibrillation.

its contribution towards this ailment. The pro-inflammatory factors like transforming growth factor- $\beta$ (TGF- $\beta$ ) [48] and nuclear factor- $\kappa \mathrm{B}$ $(\mathrm{NF}-\mathrm{kB})$ are reported to be the upstream regulators of miR-29 [49].

\section{miR-26, miR-328 and miR-499: Role in regulation of ion} channels

The miR-26 family (miR-26a-1, miR-26a-2 and miR-26b) can increase susceptibility to AF by altering the inward rectifier potassium current $\left(\mathrm{I}_{\mathrm{K} 1}\right)$. $\mathrm{I}_{\mathrm{K} 1}$ is the major potassium current of myocardial repolarization, which partially regulate cell excitability and APD. The lower expression of miR-26 in patients with $\mathrm{AF}$ and murine atrial tissue induces KIR2.1 and KCNJ2 expression and shortens APD [29], suggesting that the downregulation of miRNA-26 promotes the formation of AF. MiR-26 activates T cell nuclear factor. An elevated $\mathrm{T}$ cell nuclear factor in atrial tissue, in turn, reduces the expression of miR-26, leading to the increase in inward rectifier current.

MiR-328 is involved in a variety of physiological and pathological processes of tissue organization, such as the formation of senile dementia [50], primary biliary cirrhosis [51] and chronic bladder pain syndrome [52]. AF is a characterized by abnormal excitability via myocardial calcium overload (e.g. the outflow rate of calcium ions), potentiating the development and maintenance of AF [53]. It has been reported that miR-328 plays an essential role in development of $\mathrm{AF}$
[54]. Through microarray analysis, a recent study has shown a 3.5 fold increase in the miR-328 level in eight week samples from a right atrial tachyarrhythmia canine model compared with control. It has also been shown that overexpression of miR-328 increases the susceptibility of animals towards AF, whereas blocking its expression through chemicals or gene knockdown reduces it. In-silico analysis has revealed that calcium channel regulatory genes, such as CACNA1C and CACNB1 (L-type calcium channels $\alpha 1 c$ and $\beta 1$ subunit, respectively), are the targets of miR-328 [36]. MiR-328-mediated inhibition of the L-type calcium channels results in shortening of the action potential duration enhancing the risk of AF development [55]. Furthermore, the expression of miR-328 was found to have a positive correlation with left atrial diameter, suggesting that miR-328 plays a central role in atrial electrical activity.

Mir-499 has been recently shown to target KCNN3 which encodes the small-conductance $\mathrm{Ca}^{2+}$-activated $\mathrm{K}^{+}$channel 3 (SK3) and potentially contribute to the electrical remodeling event in AF [37].

\section{miR-1 and miR-133: Role in regulation of $\mathrm{Ca}^{2+}$ cycling}

Mir-1 and miR-133 are two major muscle-specific miRNAs whose deregulation has been associated with the extrasystolic spontaneous $\mathrm{Ca}^{2+}$ release from sarcoplasmic reticulum and the generation of arrythmogenesis after depolarization [22,56]. Increased occurrence of spontaneous $\mathrm{Ca}^{2+}$ release at the molecular level was found to be due the dissociation of ryanodine receptors (RyR2s) with the protein phosphatase (PP2A) resulting in increased phosphorylation of RyR2s. In canine model of heart failure, high levels of miR-1 and miR-133 were found to be correlated with the down regulation of the regulatory and catalytic subunits (B56 a and B56 3 ) of PP2A and the subsequent increase in calcium/calmodulin-dependent protein kinase II (CaMKII) mediated RyR2 hyperphosphorylation resulting in $\mathrm{Ca}^{2+}$ release [57].

\section{Role of miRNAs in the Maintenance of AF}

$\mathrm{AF}$ is maintained by a variety of factors. For example, local atrial structural remodeling (atrial dilatation, tissue fibrosis and scarring etc.) contributes to the formation of reentry substrate resulting in the abnormalities of the atrial internal electrical conduction. The miRNA-mediated regulation of the connective tissue growth factor (CTGF), lysyl oxidase (LOX) and 
renin-angiotensin-aldosterone system (RAAS) results in atrial collagen deposition and fibrosis, leading to the maintenance of AF [58].

\section{miR-21 and miR-590: Role in collagen deposition}

MiR-21 is involved in a variety of cancers and participates in tumor cell apoptosis, invasion and metastasis [59]. In the cardiovascular system, however, miR-21 leads to atrial fibrosis and structural remodeling and increases the risk and duration of AF [60]. MiR-21 has shown to increase the risk of AF. The phosphatase and tensin homolog gene (PTEN) has been identified as a miR-21 target gene. The PTEN-Akt pathway participates in extracellular matrix (ECM) remodeling in atria through MMP2 regulation which leads to atrial fibrosis $[27,28]$. A recent study has identified another target of miR-21 called sprouty homolog 1 (Spry1) jointly involved in the regulation of atrial fibrosis [58]. The lower Spryl level activates the mitogen-activated protein kinase (MAPK) signaling pathway, increases the number of fibers, and promotes the secretion of growth factors, leading to myocardial fibrosis and tissue remodeling [61,62]. Angiotensin II (Ang II)-induced factors, such as Ras-related C3 botulinum toxin substrate 1 (Rac1), CTGF and LOX, decrease the level of miR-21 resulting in increased Spryl level in atrial tissue which affects electrical conduction and atrial structure remodeling [26,58]. In mice with increasing age, transgenic cardiac overexpression of Rac1 results in spontaneous AF and fibrosis. However, the inhibition of the expression of miR-21 can effectively prevent atrial fibrosis, reducing associated risk factors for AF.

MiR-590 has recently been correlated with AF due to its role in reducing collagen production and deposition, which is a significant source of atrial fibrosis. In nicotine induced canine models, collagen content was found to be significantly increased, coincident with an increase in TGF- $\beta$ /TGF- $\beta$ RII and a decrease in miR-590 levels [33].

\section{miR-155 and miR-19: Role in activation of renin- angiotensin-aldosterone system}

MiR-155 can target the 3'-mRNA of Ang II type 1 receptor (AT1-R) and inhibit AT1-R activation. Endothelial dysfunction, vascular remodeling, and inflammation are prevented by miR-155, which slows down the changes in cardiac structure and reduces the progression of AF [34]. MiR-155 levels in atrial tissue may be reduced in patients with AF, causing AT1-R activation, and in turn leading to a series of changes in cardiac structure and myocardial tension.

It has been shown that in the newborn mouse cardiomyocyte, the high level of miR-19b significantly reduces Ang II-induced CTGF expression, decreases the accumulation of atrial ECM, and prevents atrial fibrosis [26].

\section{miR-133 and miR-590: Role in regulation of myogenesis and atrial remodeling}

MiR-133 (miR-133a and miR-133b) is involved in myoblast proliferation and differentiation. Through the next generation sequencing (Solexa), both miR133a and miR-133b were found to be upregulated during myogenesis. In $\mathrm{C} 2 \mathrm{C} 12$ myoblasts, miR-133a and miR-133b were found to inhibit proliferation and promote differentiation by regulating ERK1/2 phosphorylation. Fibroblast growth factor 1 (FGF1) and PP2Ac (PP2Aca and PP2Acb) are reported to be the potential targets of $\mathrm{miR}-133 \mathrm{a} / \mathrm{b}$ [32]. Several studies have reported that the down-regulation of miR-133 was observed in chronic cases of AF $[33,63]$. Corresponding study of the upregulation of TGF- $\beta$ and TGF- $\beta$ RII in canine model of AF confirms that TGF- $\beta$ and TGF- $\beta$ RII are miR-133 targets in atrial fibroblasts [33].

\section{miR-30 and miR-208: Role in myocardial hypertrophy/ atrial fibrosis}

Atrial fibrosis is characterized by the structural alteration and hypertrophy of cardiac myocytes. Recently dysregulated autophagy has been implicated as a leading cause of myocardial hypertrophy. In the rat model of cardiac hypertrophy, a group has reported the upregulation of an autophagy related gene beclin-1 and a corresponding decrease in the expression of miR-30 in cardiac tissue [31]. Moreover CTGF, a key pro-fibrotic protein, was also found to be a target of miR-30 in rodent model of heart disease [64], implicating a negative regulatory role of miR-30 in the maintenance of AF.

MiR-208 is mainly expressed in cardiac tissue and this family consists of miR-208a and miR-208b encoded by the intron of a cardiac muscle myosin heavy chain gene $(M y h 6)$ and $\beta$-cardiac muscle myosin heavy chain gene (Myh7), respectively [65]. Thyroid hormone-associated protein 1 (THRAP1) and myostatin, both of which are negative regulators of muscle hypertrophy, are reported targets of miR-208 family. Transgenic expression of miR-208 in murine heart has proven hypertrophic to the cardiac tissue due to decreased expression of THRAP1 and myostatin and is sufficient to induce arrhythmias [35].

\section{Summary and Perspective: miRNA in AF}

$\mathrm{AF}$ is a common clinical arrhythmia, but the mechanisms are not yet fully understood. MiRNAs assist in regulation, generation, development and maintenance of AF via modulations in ion channels, receptors and extracellular matrix proteins. Some miRNAs implicated in AF have potential for use as biomarkers and drug targets [66]. For example, serum miR-21 and miR-29 can be used as a noninvasive method for detecting AF and inhibition of miR-21 may prevent myocardial fibrosis to reduce the risk of AF. However, our current knowledge about miRNA and its contribution towards AF is still limited and therefore, learning more about miRNAs will provide new insights into their mechanisms of action and help us in determining effective treatment targets [67]. Data from different studies show that some miRNAs are causative while others have protective effect for AF depending upon their targets. For example, some are pro-fibrotic while others are anti-fibrotic. Similarly, some are pro-arrythmatic whereas others are anti-arrythmatic. Nevertheless, we can identify the deregulated ones to be associated with the disease development and/or maintainance and use them as biomarkers, at least, for that ailment. Future research in this direction is needed, including gathering of larger data sets from animal models and in-depth analysis of the role of miRNAs in the pathogenesis of AF. The definitive function of a particular miRNA can however be evaluated by the knockdown studies, after which the therapeutic potential could be assessed. The functional analysis through miRNA overexpression and their knockdown through anti-miRNA oligos can provide insight about their role in the pathogenesis and/or maintenance of a particular disease. This will help in the development of clinical trials to test miRNA-based therapeutic drugs. In case of AF there is substantial evidence regarding the role of miRNAs in the development and maintenance of the disease. Thus, the beneficial effect of using miRNA for AF seems to hold a lot of promise for future treatments and therapies. 


\section{Acknowledgements}

This work was supported by grants from National Natural Science Foundation of China (81272880), the Shanghai Committee of Science and Technology (124119b1300), Shanghai Municipal Health Bureau (2012-186) and a start-up fund of research from Jinshan Hospital (2012-2) to GX

\section{References}

1. Grönefeld GC1, Lilienthal J, Kuck KH, Hohnloser SH; Pharmacological Intervention in Atrial Fibrillation (PIAF) Study investigators (2003) Impact of rate versus rhythm control on quality of life in patients with persistent atrial fibrillation. Results from a prospective randomized study. Eur Heart J 24: 14301436

2. Chien KL1, Su TC, Hsu HC, Chang WT, Chen PC, et al. (2010) Atrial fibrillation prevalence, incidence and risk of stroke and all-cause death among Chinese.Int J Cardiol 139: 173-180.

3. Chou CC1, Nihei M, Zhou S, Tan A, Kawase A, et al. (2005) Intracellula calcium dynamics and anisotropic reentry in isolated canine pulmonary veins and left atrium.Circulation 111: 2889-2897.

4. Nattel S (2002) New ideas about atrial fibrillation 50 years on.Nature 415: 219-226.

5. Nattel S1, Harada M2 (2014) Atrial remodeling and atrial fibrillation: recent advances and translational perspectives.J Am CollCardiol 63: 2335-2345.

6. Nattel S1, Burstein B, Dobrev D (2008) Atrial remodeling and atrial fibrillation: mechanisms and implications.CircArrhythmElectrophysiol 1: 62-73.

7. Van Wagoner DR, Nattel S (2008) Insights into mechanisms linking cardiac hypertrophy and atrial fibrosis: evidence for a role of histone deacetylase in atrial fibrillation pathophysiology and therapy.J Mol Cell Cardiol 45: 707-708.

8. Guo H1, Ingolia NT, Weissman JS, Bartel DP (2010) Mammalian microRNAs predominantly act to decrease target mRNA levels.Nature 466: 835-840.

9. Bartel DP (2004) MicroRNAs: genomics, biogenesis, mechanism, and function.Cell 116: 281-297.

10. Bartel DP (2009) MicroRNAs: target recognition and regulatory functions.Cell 136: $215-233$.

11. Nilsen TW (2007) Mechanisms of microRNA-mediated gene regulation in animal cells. Trends Genet 23: 243-249.

12. Hashimoto $Y 1$, Akiyama $Y$, Yuasa $Y$ (2013) Multiple-to-multiple relationships between microRNAs and target genes in gastric cancer.PLoS One 8: e62589.

13. Cai X1, Hagedorn $\mathrm{CH}$, Cullen $\mathrm{BR}$ (2004) Human microRNAs are processed from capped, polyadenylated transcripts that can also function as mRNAs. RNA 10: 1957-1966.

14. Lee Y1, Ahn C, Han J, Choi H, Kim J, et al. (2003) The nuclear RNase III Drosha initiates microRNA processing.Nature 425: 415-419.

15. Denli AM1, Tops BB, Plasterk RH, Ketting RF, Hannon GJ (2004) Processing of primary microRNAs by the Microprocessor complex.Nature 432: 231-235.

16. Yi R1, Qin Y, Macara IG, Cullen BR (2003) Exportin-5 mediates the nuclear export of pre-microRNAs and short hairpin RNAs.Genes Dev 17: 3011-3016.

17. Gregory RI1, Yan KP, Amuthan G, Chendrimada T, Doratotaj B, et al. (2004) The Microprocessor complex mediates the genesis of microRNAs.Nature 432: 235-240.

18. Reinhart BJ1, Slack FJ, Basson M, Pasquinelli AE, Bettinger JC, et al. (2000) The 21-nucleotide let-7 RNA regulates developmental timing in Caenorhabditiselegans.Nature 403: 901-906.

19. Urbich C1, Kuehbacher A, Dimmeler S (2008) Role of microRNAs in vascular diseases, inflammation, and angiogenesis.Cardiovasc Res 79: 581-588.

20. Jakob P1, Landmesser U (2012) Role of microRNAs in stem/progenitor cells and cardiovascular repair.Cardiovasc Res 93: 614-622.
21. Lionetti V1, Ventura C (2013) Regenerative medicine approach to repair the failing heart.VasculPharmacol 58: 159-163.

22. Kim GH (2013) MicroRNA regulation of cardiac conduction and arrhythmias Transl Res 161: 381-392.

23. Xiao J1, Liang D, Zhang Y, Liu Y, Zhang H, et al. (2011) MicroRNA expression signature in atrial fibrillation with mitral stenosis.Physiol Genomics 43 655-664.

24. Liu H, Chen GX, Liang MY, Qin H, Rong J, et al. (2014) Atrial fibrillation alters the microRNA expression profiles of the left atria of patients with mitral stenosis.BMC CardiovascDisord 14: 10

25. Belevych AE1, Sansom SE, Terentyeva R, Ho HT, Nishijima Y, et al. (2011) MicroRNA-1 and -133 increase arrhythmogenesis in heart failure by dissociating phosphatase activity from RyR2 complex.PLoS One 6: e28324.

26. Gao S1, Liu TW, Wang Z, Jiao ZY, Cai J, et al. (2014) Downregulation of microRNA-19b contributes to angiotensin II-induced overexpression of connective tissue growth factor in cardiomyocytes.Cardiology 127: 114-120.

27. Charles NJ1, Huebert RC, Lee S, Adhikari N, Polster S, et al. (2010) Targeted Sprouty1 overexpression in cardiac myocytes does not alter myocardial remodeling or function.Mol Cell Biochem 342: 57-62.

28. Thum T1, Gross C, Fiedler J, Fischer T, Kissler S, et al. (2008) MicroRNA-2 contributes to myocardial disease by stimulating MAP kinase signalling in fibroblasts. Nature 456: 980-984

29. Luo X1, Pan Z, Shan $H$, Xiao J, Sun X, et al. (2013) MicroRNA-26 governs profibrillatory inward-rectifier potassium current changes in atrial fibrillation.J Clin Invest 123: 1939-1951.

30. Dawson K1, Wakili R, Ordög B, Clauss S, Chen Y, et al. (2013) MicroRNA29 a mechanistic contributor and potential biomarker in atrial fibrillation.Circulation 127: 1466-1475, 1475e1-28.

31. Pan W1, Zhong Y, Cheng C, Liu B, Wang L, et al. (2013) MiR-30-regulated autophagy mediates angiotensin II-induced myocardial hypertrophy.PLoS One 8: e53950

32. Feng Y1, Niu LL, Wei W, Zhang WY, Li XY, et al. (2013) A feedback circuit between miR-133 and the ERK1/2 pathway involving an exquisite mechanism for regulating myoblast proliferation and differentiation.Cell Death Dis 4: e934.

33. Shan H1, Zhang Y, Lu Y, Zhang Y, Pan Z, et al. (2009) Downregulation of miR-133 and miR-590 contributes to nicotine-induced atrial remodelling in canines.Cardiovasc Res 83: 465-472.

34. Martin MM1, Buckenberger JA, Jiang J, Malana GE, Nuovo GJ, et al. (2007) The human angiotensin II type 1 receptor $+1166 \mathrm{~A} / \mathrm{C}$ polymorphism attenuates microRNA-155 binding.J BiolChem 282: 24262-24269.

35. Callis TE1, Pandya K, Seok HY, Tang RH, Tatsuguchi M, et al. (2009) MicroRNA-208a is a regulator of cardiac hypertrophy and conduction in mice.J Clin Invest 119: 2772-2786.

36. Bodi I1, Mikala G, Koch SE, Akhter SA, Schwartz A (2005) The L-type calcium channel in the heart: the beat goes on.J Clin Invest 115: 3306-3317.

37. Ling TY1, Wang XL, Chai Q, Lau TW, Koestler CM, et al. (2013) Regulation of the SK3 channel by microRNA-499--potential role in atrial fibrillation.Heart Rhythm 10: 1001-1009.

38. Alegret JM1, Aragonès G, Elosua R, Beltrán-Debón R, Hernández-Aguilera A, et al. (2013) The relevance of the association between inflammation and atrial fibrillation.Eur J Clin Invest 43: 324-331.

39. Farmakis D1, Parissis J2, Filippatos G3 (2014) Insights into onco-cardiology: atrial fibrillation in cancer.J Am CollCardiol 63: 945-953

40. Goette A1, Honeycutt C, Langberg JJ (1996) Electrical remodeling in atria fibrillation. Time course and mechanisms.Circulation 94: 2968-2974.

41. Roderburg C1, Urban GW, Bettermann K, Vucur M, Zimmermann $\mathrm{H}$, et al. (2011) Micro-RNA profiling reveals a role for miR-29 in human and murine liver fibrosis. Hepatology 53: 209-218. 
42. Cushing L1, Kuang PP, Qian J, Shao F, Wu J, et al. (2011) miR-29 is a major regulator of genes associated with pulmonary fibrosis.Am J Respir Cell MolBiol 45: 287-294.

43. Boon RA1, Seeger T, Heydt S, Fischer A, Hergenreider E, et al. (2011) MicroRNA-29 in aortic dilation: implications for aneurysm formation.Circ Res 109: $1115-1119$.

44. Emilsson L1, Smith JG, West J, Melander O, Ludvigsson JF (2011) Increased risk of atrial fibrillation in patients with coeliac disease: a nationwide cohort study.Eur Heart J 32: 2430-2437.

45. Ahlehoff $\mathrm{O} 1$, Gislason $\mathrm{GH}$, Jørgensen $\mathrm{CH}$, Lindhardsen J, Charlot M, et al (2012) Psoriasis and risk of atrial fibrillation and ischaemic stroke: a Danish Nationwide Cohort Study.Eur Heart J 33: 2054-2064.

46. Li H1, Scherlag BJ, Kem DC, Zillner C, Male S, et al. (2013) Atrial tachycardia provoked in the presence of activating autoantibodies to $\hat{I}^{2} 2$-adrenergic receptor in the rabbit.Heart Rhythm 10: 436-441.

47. Frustaci A1, Chimenti C, Bellocci F, Morgante E, Russo MA, et al. (1997) Histological substrate of atrial biopsies in patients with lone atrial fibrillation. Circulation 96: 1180-1184.

48. Zhang Y, Huang XR, Wei LH, Chung AC, Yu CM, et al. (2014) miR-29b as a therapeutic agent for angiotensin II-induced cardiac fibrosis by targeting TGF-Î²/Smad3 signaling.MolTher 22: 974-985

49. Mott JL1, Kurita S, Cazanave SC, Bronk SF, Werneburg NW, et al. (2010) Transcriptional suppression of mir-29b-1/mir-29a promoter by c-Myc, hedgehog, and NF-kappaB.J Cell Biochem 110: 1155-1164.

50. Boissonneault V1, Plante I, Rivest S, Provost P (2009) MicroRNA-298 and microRNA-328 regulate expression of mouse beta-amyloid precursor protein-converting enzyme 1.J BiolChem 284: 1971-1981.

51. Padgett KA1, Lan RY, Leung PC, Lleo A, Dawson K, et al. (2009) Primary biliary cirrhosis is associated with altered hepatic microRNA expression.J Autoimmun 32: 246-253.

52. Sanchez Freire V1, Burkhard FC, Kessler TM, Kuhn A, Draeger A, et al. (2010) MicroRNAs may mediate the down-regulation of neurokinin-1 receptor in chronic bladder pain syndrome.Am J Pathol 176: 288-303.

53. Mancarella S1, Yue Y, Karnabi E, Qu Y, El-Sherif N, et al. (2008) Impaired $\mathrm{Ca} 2+$ homeostasis is associated with atrial fibrillation in the alpha1D L-type Ca2+ channel KO mouse.Am J Physiol Heart CircPhysiol 295: H2017-2024.

54. Lu Y1, Zhang Y, Wang N, Pan Z, Gao X, et al. (2010) MicroRNA-328 contributes to adverse electrical remodeling in atrial fibrillation.Circulation 122 : 2378-2387.
55. Sood S1, Chelu MG, van Oort RJ, Skapura D, Santonastasi M, et al. (2008) Intracellular calcium leak due to FKBP12.6 deficiency in mice facilitates the inducibility of atrial fibrillation. Heart Rhythm 5: 1047-1054.

56. Terentyev D1, Belevych AE, Terentyeva R, Martin MM, Malana GE, et al. (2009) miR-1 overexpression enhances $\mathrm{Ca}(2+)$ release and promotes cardiac arrhythmogenesis by targeting PP2A regulatory subunit B56alpha and causing CaMKII-dependent hyperphosphorylation of RyR2.Circ Res 104: 514-521.

57. Nishijima $Y 1$, Feldman DS, Bonagura JD, Ozkanlar $Y$, Jenkins $P J$, et al. (2005) Canine nonischemic left ventricular dysfunction: a model of chronic human cardiomyopathy.J Card Fail 11: 638-644.

58. Adam O1, Löhfelm B, Thum T, Gupta SK, Puhl SL, et al. (2012) Role of miR21 in the pathogenesis of atrial fibrosis.Basic Res Cardiol 107: 278.

59. Roy S1, Khanna S, Hussain SR, Biswas S, Azad A, et al. (2009) MicroRNA expression in response to murine myocardial infarction: miR-21 regulates fibroblast metalloprotease-2 via phosphatase and tensin homologue.Cardiovasc $\operatorname{Res} 82:$ 21-29.

60. Goudis CA1, Kallergis EM, Vardas PE (2012) Extracellular matrix alterations in the atria: insights into the mechanisms and perpetuation of atrial fibrillation. Europace 14: 623-630.

61. Adam O1, Theobald K, Lavall D, Grube M, Kroemer HK, et al. (2011) Increased lysyl oxidase expression and collagen cross-linking during atria fibrillation.J Mol Cell Cardiol 50: 678-685.

62. Nickenig G1, Harrison DG (2002) The AT(1)-type angiotensin receptor in oxidative stress and atherogenesis: Part II: AT(1) receptor regulation.Circulation 105: 530-536.

63. Li H1, Li S, Yu B, Liu S (2012) Expression of miR-133 and miR-30 in chronic atrial fibrillation in canines.Mol Med Rep 5: 1457-1460.

64. Duisters RF, Tijsen AJ, Schroen B, Leenders JJ, Lentink V, et al. (2009) miR133 and miR-30 regulate connective tissue growth factor: implications for a role of microRNAs in myocardial matrix remodeling. Circ Res 104:170-178.

65. vanRooij E1, Sutherland LB, Qi X, Richardson JA, Hill J, et al. (2007) Contro of stress-dependent cardiac growth and gene expression by a microRNA. Science 316: 575-579.

66. Zhao Z1, Liu T, Wang X, Li G (2013) MicroRNAs as novel antiarrhythmic targets for atrial fibrillation.Int J Cardiol 168: e135-137.

67. Shi KH1, Tao H, Yang JJ, Wu JX, Xu SS, et al. (2013) Role of microRNAs in atrial fibrillation: new insights and perspectives.Cell Signal 25: 2079-2084. 